\title{
Provision of Training for the IT Industry: The ELEVATE Project
}

\author{
Iraklis Paraskakis ${ }^{1,4}$, Andreas Konstantinidis ${ }^{1}$, Thanassis Bouras ${ }^{2}$, Kostas Perakis ${ }^{2}$, \\ Stelios Pantelopoulos ${ }^{3}$, and Thanos Hatziapostolou ${ }^{4}$ \\ ${ }^{1}$ South East European Research Centre (SEERC), Research Centre of the \\ University of Sheffield and CITY College, \\ 24 Pr. Koromila Str, 54622 Thessaloniki, Greece \\ ${ }^{2}$ UBITECH Research, \\ 429 Messogion Ave., Ag. Paraskevi Square, 15343 Athens, Greece \\ ${ }^{3}$ SingularLogic, S.A \\ Al. Panagouli \& Siniosoglou, N. Ionia 14234 Athens, Greece \\ ${ }^{4}$ Department of Computer Science, CITY College, International Faculty of the \\ University of Sheffield, \\ 13 Tsimiski Str, 54622 Thessaloniki, Greece \\ \{iparaskakis, ankonstantinidis\} @seerc.org, \\ \{bouras, kperakis\}@ubitech.eu, spantelopoulos@singularlogic.eu, \\ a.hatziapostolou@city.acdemic.gr
}

\begin{abstract}
This paper will present ELEVATE that aims to deliver an innovative training, educational and certification environment integrating the application software to be taught with the training procedure. ELEVATE aspires to address the training needs of software development SMEs and the solution proposed is based on three basic notions: to provide competence training that is tailored to the needs of the individual trainee, to allow the trainee to carry out authentic activities as well as problem based learning that draws from real life scenarios and finally to allow for the assessment and certification of the skills and competences acquired. In order to achieve the desired results the ELEVATE architecture utilises an Interactive Interoperability Layer, an Intelligent Personalization Trainer as well as the Training, Evaluation \& Certification component. As an end product, the ELEVATE project The ELEVATE pedagogical model is based on blended learning, the e-Training component (an intelligent system that provides tailored training) and Learning 2.0.
\end{abstract}

Keywords: Competence training, blended learning, authentic learning, problem based learning, pedagogical methodology and model for training.

\section{Introduction}

There are currently some 22 million SMEs across Europe employing almost 120 million people and contributing 57 per cent of pan-European gross domestic product. However, the European enterprises suffer particularly from personnel provided with updated technological skills and are poorly informed and/or interested in professional 
training opportunities with which they could increase their know-how assets. In addition, the professional training programs that both SMEs and professionals resort to are not always the most suitable.

Moreover, the introduction of multi-oriented, separate application software (e.g. ERP and CRM) and vendor-driven solutions, which increases the complexity of systems installation, customization, administration and use, making the support of these systems a challenging task, extends the IT gap across the enlarged Europe, consisting of both a competence gap in the existing workforce as well as a shortage of available certified professionals.

The ELEVATE environment aspires to be a hybrid training and certification environment, which integrates the application software to be taught in a pedagogicaldocumented educational process, allowing the software development SMEs to deliver innovative e-training services and to address the needs of their business partners and customers. Moreover, ELEVATE anticipates to deliver technology know-how in the fields of e-learning, educational content aggregation and material creation, learning management system and application software integration, and pedagogic standards and models.

In the following sections, we present the background knowledge and rationale on which the proposition of the ELEVATE environment is to be based. Following that we elaborate upon the project objectives, as well as aspects of the expected results. Finally, we discuss the current state of the project and conclude by indicating future steps and work.

\section{ELEAVATE's Rationale and Objectives}

In this section, we justify the conceptualization of the ELEVATE project by presenting the background information which was studied and considered prior to its conception. Through this discussion, we rationalize the necessity of such a project and present the vision and end goals of the project members.

\subsection{Provision of Training in the IT Sector: Background}

The rapid structural changes in the software industry, comprising mostly of software development SMEs, that deliver and introduce new technologies and application software in the workplace, produce a shift of employment realities. These realities, in turn, require updated application software competencies and technological skills. The same circumstances result in the need for people to recognise that they cannot rely on earning their living in a particular occupation throughout their life, and must increasingly take responsibility for acquiring updated, and often quite different, application software skills as their career progresses.

Training in application software tools and systems has gained from the outset a central position in e-learning activities, particularly in the corporate world, as the software development SMEs who developed these innovative technology applications were the first to realize the use of e-learning and e-training for covering educational needs in their field. Nevertheless, this rather long history in application software training and e-learning has not been fruitful enough, as it has not been accompanied by a 
corresponding lead at the level of pedagogic quality of this training. What is essentially absent - as the software development SMEs are not capable of providing - from current application software training and e-learning, is the explicit selection of educational approaches which treat the application-to-be-learned as a tool for everyday use, for the learning of which, as has always been the case with human tools, the trainee should sit at the feet of an experienced user of the tool, having the opportunity as an apprentice not just to observe, but mainly to try, interact and participate.

More specifically, the implementation of the application software training is currently based on the simple demonstration of the application to be taught, and on the descriptive analytical presentation of the functionalities of the software application, or on the interaction with a simulation application of the application software to be taught giving the end-user a limited feeling of how the application is used in real life conditions. Besides this weakness, another result is that the learning content integrated with current e-learning systems is costly and static, and, in case of IT software upgrade should be redesigned and recreated.

We claim that e-learning and e-training in application software in conjunction with sophisticated educational approaches and pedagogic models have the potential to become the locomotives in driving growth and creating more and better jobs in Europe. Towards this direction, ELEVATE aspires to introduce a highly innovative combination of services aiming to enable enterprises and organizations to drive productivity through learning content management, knowledge sharing, assessment, rapid authoring, and performance support.

The vision ELEVATE is to leverage e-learning, interoperability and pedagogical know-how into the training services of the software SMEs, in order to elevate the quality of the existing application software products of the software SMEs. Moreover, through the ELEVATE solution software SMEs will be able to provide their clients as well as their business partners and individuals (i.e. professionals and application software users) with a holistic e-learning, educational process monitoring and certification environment adjustable to each application software for training the end-user in realistic conditions.

\subsection{ELEVATE's Objectives}

To accomplish the vision mentioned above, the ELEVATE project has a three-fold focus that will be achieved through the following research and innovation related activities:

\section{- Objective I}

to interactively integrate and fruitfully combine the application software to be taught with the personalised training and educational procedure, providing realtime interoperability and interaction with the e-learning environment in the scope of training process improvement and efficient monitoring of the trainee.

\section{- Objective II}

to validate and evaluate the research results by developing proof-of-concept SMEs-specific prototypes, demonstrating the innovative ELEVATE pedagogic approach and educational and certification environment in the training procedure of the application software products of the participating software SMEs. 
- Objective III

to facilitate the take-up of the ELEVATE research results by the software development SMEs. That is, there will be formal adoption guidelines for the successful integration and effective deployment of the ELEVATE environment in application software products addressing real-life scenarios. Moreover, there will be a focus on training activities that are aimed at technical and managerial staff of the participating software development SMEs.

\section{Eleavate's Pedagogical Methodology}

One of the fundamental trends in e-Learning is capturing the attention of the user or student, which is competed by many other media and platforms constantly. Therefore the educational content must be engaging enough to keep the student dedicated to the learning activities. [1] gives a list of study background in capturing the attention of and engaging the learner. Therefore e-learning is not just compiling information and making it available to the learner but rather creating an environment where the learner continuously adds up to his or her knowledge in an effective and permanent fashion.

In addition, the emergence and prominence of the World Wide Web, with its new possibilities of communities, is thus considered the "new pedagogy of learning" [2]. It is therefore imperative that an approach is based on the online learning community principles. Web 2.0, the new approach based on Internet communities, also encourages significantly more interaction between users, a feature that many theorists argue is vital in e-learning. Interaction encourages deeper and more active learning engagement, builds communities of learning [3] and enables feedback from tutors to students. [4] In recent studies, associations have been reported between tutor-student interaction in online learning and raised levels of student motivation. [5], [6]. Finally, growing spectrums of applications are enumerated as several emerging technologies and applications under the Web 2.0 platform [7]. These include RSS, wikis, blogs, and the user comment functionality found in various websites.

Based on the above, as well as other bibliographical research, the ELEVATE environment incorporates principles regarding the theoretical and applied pedagogy, emphasising at the theories of social interactionism, constructivism, and socio-cultural and activity theory. Moreover the pedagogical methodology purported by ELEVATE facilitates the development of specialised e-learning methodology concerning the training in application software skills. This is to be explored through the notion of competences and how these are best taught and acquired for the IT sector. Given the need for competence development, an integral part of this is the assessment and certification of the acquired competences. Thus, it is imperative to create a theoretical underpinning for the evaluation process as well the application software skills certification procedure.

The pedagogical methodology to be explored and used in ELEVATE is based on three basic notions: the notion of blended learning, the notion of Learning 2.0 and finally on the notion that there needs to be an approach that does not fit all but rather tailors the training on the needs of the individual. That is material used for training, is selected in order to suit the learning needs of the specific trainee in the specific circumstances. Moreover it is anticipated that the selected material will further facilitate the learning experience of that individual. 
The pedagogic elements (see Fig. 1) comprising the innovative characteristics of the ELEVATE e-learning environment are structurally broken down into three main modules: blended learning, the e-Training and Learning 2.0.

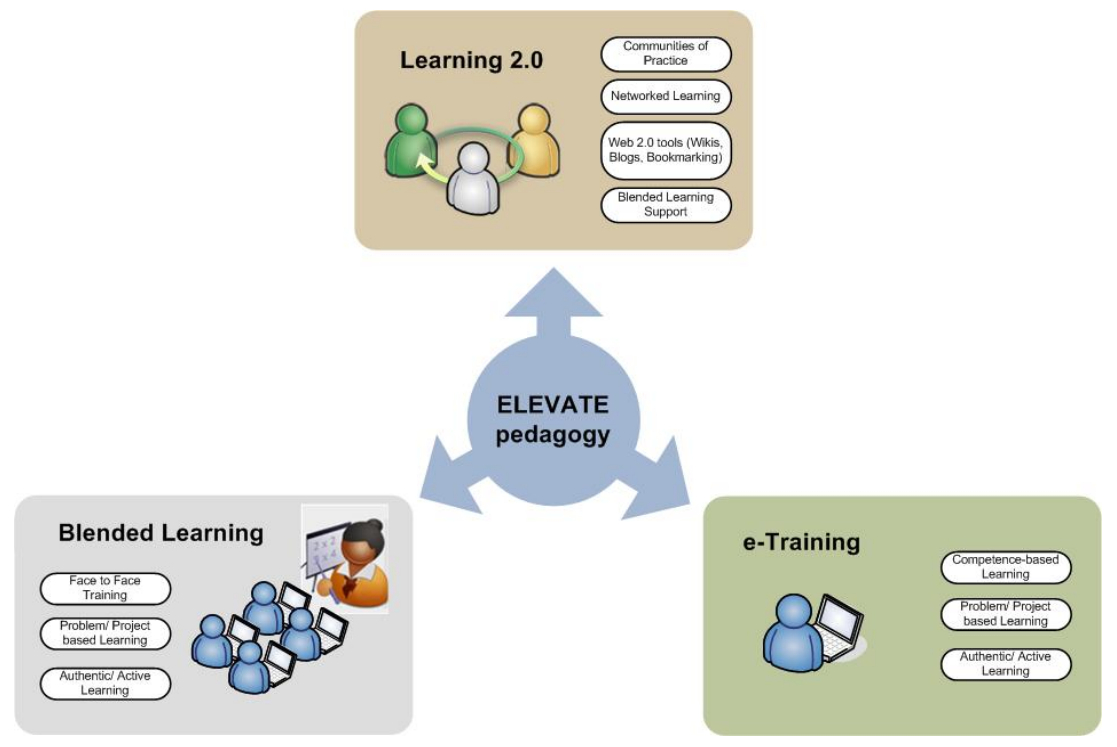

Fig. 1. The proposed ELEVATE Pedagogical Methodology

\subsection{Blended Learning}

The pedagogical methodology envisioned in ELEVATE incorporates a blended learning cycle, which would include alternating sessions of distance learning and face to face training. In addition, approaches such as problem, competence and authentic/active learning will be explored.

Learning Management Systems (LMSs) are widely used to support blended learning. Learning based on the blending of face-to-face with online training, of formal and informal learning is more acceptable among SMEs than online-training alone. Evidence suggests that the learning experience is better and completion rates are greater where there is tutor support either face to face, on-line or over the telephone.

An LMS is a web-based system used to organise and coordinate the learning material of an educational institution. LMSs also facilitate communication and collaboration of the trainees through the support of communication, collaboration and Web2.0 tools such as forums, blogs, wikis, chat rooms etc.

The blended learning approach of the ELEVATE solution includes the following: (a) face to face training, (b) problem/project based learning, (c) authentic/active learning.

The LMS can be used in a preoperational manner, which is before a face to face class is being held. During this preoperational phase, the trainee may be given some cases studies to consider, some real scenarios to consider and propose solutions and explore them during the face to face session. Some of the advantages of traditional 
face to face classroom education are: (a) social interaction through personal contact and the exchange of ideas, (b) familiarity, customary method, and (c) an environment which supports multiple communication channels.

Also the LMS can be used in a post operational manner as well. This way, the LMS can be used to further support the learning needs of the learner following the face to face session. Such support can be in the form of further discussion, between the trainer and the trainees, or indeed discussion between the trainees themselves. Particularly the later option gives rise to Learning 2.0.

Moreover, if during the face to face or afterwards, an individual trainee feels that there are aspects of the training session that need further work, this can be achieved via the e-Training module of the ELEVATE pedagogical model.

\section{2 e-Training}

For the e-Training aspect of the ELEVATE solution we examined the following pedagogical approaches: 1) Authentic Learning, 2) Competence Based Learning, 3) Problem Based Learning, and 4) Project Based Learning, More specifically, for the easier transition of the acquired skills to the real life working environment, an authentic learning approach for the e-Training solution has been proposed. Authentic learning advocates that individuals should engage and interact with authentic activities thus facilitating the transition of the simple application end-user to a trainee. In addition, through competency-based learning environments learners are confronted with authentic, open problems and learning materials which have personal meaning for them and are presented in a variety of formats. For e-Training to operate, the major phases are as follows:

(a) Training Object Generation,

(b) Training and

(c) Evaluation.

During the Training object generation, the trainer/domain expert generates the initial training object by capturing the DOM tree changes caused by his/her activities. During the Training, the trainer provides the necessary metadata enrichment for the enrichment of the training object. The metadata will be used by e-Training to facilitate its tutoring capabilities. Finally, in the evaluation phase, the trainee, is modelled in order to update its profile. The information gathered is used by e-Training system to adopt and personalise the material according to the learning needs of the individual trainee.

\subsection{Learning 2.0}

Within the scope of Learning 2.0, a pedagogy empowered by digital and network technology, three needs should be satisfied: (a) a learning objects repository (through the implementation of a learning management system), (b) a framework supporting networked learning and the development of communities of practice (through web2.0 tools such as wikis, blogs, social bookmarking etc) and (c) the distance training segment of a blended learning approach (covering distance learning). In Learning 2.0 the trainee is not merely a consumer of the various digital contents but also have the ability to 
produce content himself/herself as well as create Communities of Practice (CoP) and other networks that best suits the needs of the individual.

Communities of Practice are a set of relations among persons and activities over time and in relation with other tangential and overlapping CoPs [8]. Members of CoPs have a shared set of interests and are motivated to do something about them. In addition, CoPs are self-generating, the membership is self selecting and they are not necessarily co-located.

LMSs can also be utilised to facilitate the creation of online communities. Online communities are a key factor in the development of the Internet based society and business models. In online communities, users interact with each other, share information and cooperate, forming specialized groups either according to common interests or demographic criteria.

\subsection{Assessing and Certifying Competences in ELEVATE}

It should also be noted that the proposed ELEVATE project supports the integration of advanced, value-added e-training capabilities, based on widely-accepted pedagogic models, into commercial off-the-shelf software products and solutions, embedding the software to be taught into the pedagogical-documented educational procedure. Thus, the ELEVATE environment will enable the acquisition of technological skills and competencies in the application software taught, transferring innovative know-how to the e-training process. More specifically,

- at the technological level, the ELEVATE Training, Educational and Certification Environment enables the complete, interactive integration of the e-learning platforms and tools, utilized for both synchronous and asynchronous e-learning services, with pre-selected software applications products, which constitutes the educational subject, and is supplemented by innovative assisting and training tools, aiming to provide personalized training and educational services;

- at the pedagogical level, the pedagogical-documented ELEVATE Training, Educational and Certification Environment improves the quality of the provided professional e-training services, enables the trainee to become a real end-user of the application software product taught in pragmatic usage scenarios, facilitates the simple application end-user to turn instantly into a trainee, offers mature conditions of apprenticeship development, even with the natural and electronic absence of an experienced application user (or trainer), offers new potentials for interactive e-learning content aggregation, dynamic creation and maintenance, and adopts a widely known and accepted frameworks concerning the monitoring and the evaluation of the e-learning procedure, supporting an automated process regarding the certification of competencies on specific application software products;

\section{ELEVATE's Architecture: A Bird's Eye View}

The ELEVATE environment constitutes an innovative bridge that represents a critical, added-value element developing an integrated virtual asynchronous e-learning environment prototype, specialized in the training and acquisition of application software competencies. In particular, the ELEVATE environment comprises of three 
subsystems (presented in Fig. 2, which also presents the involved functional components and subsystems, as well as the communication channels among them):

- the Interactive Interoperability Layer (IIL), which develops the technical preconditions required in order the trainee to be able to use and interact, for training purposes, with the application software (to be taught), instead of using an inflexible and inadequate simulation environment. IIL facilitates the context-sensitive access of the trainee to the components and the functionality of the application software being taught, regarding the learning and training level of the trainee.

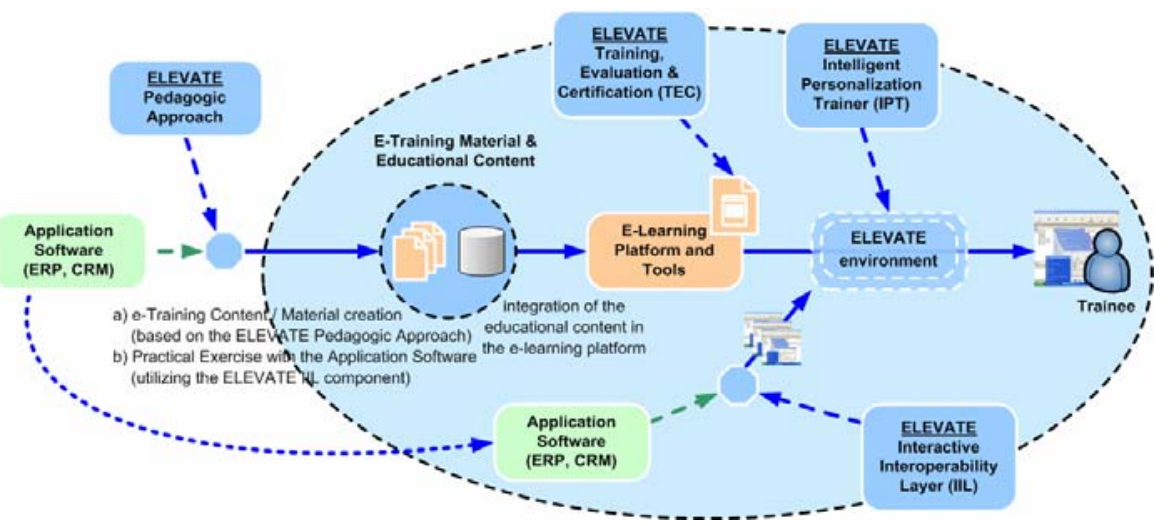

Fig. 2. A bird's eye view of the ELEVATE architecture

- the Intelligent Personalization Trainer (IPT) that defines each end-user's access rights to several training areas of the e-learning environment depending on his/her competencies level. IPT ensures intelligent access to the digital learning content, to the appropriate step of the training process and to the suitable components of the application software to be taught. This functionality is provided by bi-directional links and interfaces among the e-learning training and evaluation modules of the e-learning platform and the structural components of the application software.

- the Training, Evaluation \& Certification (TEC) subsystem that is the support of pedagogic activities regarding the knowledge and competencies evaluation. TEC is a typical system for automatic evaluation including tools for creating queries of several types (e.g. multiple choices), tools for composing tests, an organized exercises repository, test and exercises interfaces, and mechanisms for performance assessment.

Finally, the ELEVATE educational and certification environment supports the usage of introductory evaluation test to assess the initial competency level of the potential trainee regarding a specific application software product. The results of the introductory skills examination provide the information required to the IPT to propose traineespecific learning paths.

The pedagogic elements comprising the innovative characteristics of the ELEVATE e-learning environment are structurally broken down in three main modules: 
- E-Training Material Creation:

integration of various tools that facilitate the dynamic design and creation of e-learning digital content related to the learning environment and the application software being taught,

- Synchronous E-Learning:

Virtual Classroom, comprising both online learning courses and practical training, creating a so-called virtual classroom that is coordinated and guided by a specialized tutor (trainer), and

- Asynchronous E-Learning and Learning Management System:

constituting the "self-paced" mode of the ELEVATE educational environment that enables the trainee to determine his training progression on his own.

\section{Conclusions and Future Work}

Currently, ELEVATE, is about to conclude the field study, in order to capture the user requirements of the specific SMEs that are partners in the project. During the detailed requirements analyses, interviews and studies of specific software products, certain aspects have surfaced and discovered to be in common while a number of differences were also observed. The ELEVATE solution will utilise an LMS as the basis of training provision by the software developers. The face to face has proved an important aspect of the training session that software companies are keen to maintain, since it provides them a link with their customers and resellers. On the other hand the ELEVATE SME participants are very keen to harness the opportunities offered by ICT in order to streamline the training services that they offer and maximise opportunities. Although the various solutions that are going to be developed within ELEVATE are targeted not only for the SME partners but also for the general European software technology SMEs, it is also a necessity that the final deliverable product should fulfill the requirements of the SME participants in the best way possible.

Therefore, there is a trade-off between complying with the immediate requirements of the specific SMEs and building up a system that is to offer generic solutions to European software technology SMEs with rich innovative methods. ELEVATE will then choose a medium way that should both serve the needs of the SMEs partners but also press innovation at the same time.

Regarding future work the project will strive to develop a pedagogically-documented approach and model that facilitates the specialized and personalized e-training of professionals and end-users in application software products. To accomplish this, related work and pedagogical models will be studies. The main focus will be on competence based learning (CBL). More specifically, CBL is based on the fundamental idea of knowledge space theory that a person's knowledge state in a certain domain can be understood as the set of problems this person is able to solve [9].

In conclusion, according to the above and based on sound pedagogical and psychological principles, we will proceed to propose our ELEVATE pedagogical methodology. 


\section{References}

1. Conrad, R.M., Donaldson, J.A.: Engaging the Online Learner Activities and Resources for Creative Instruction. John Wiley and Sons, Jossey-Bass, San Francisco (2004)

2. Muske, G., Goetting, M., Vukonick, M.: The World Wide Web: A Training Tool for Family Resource Management Educators. Journal of Extension 39(4) (2001), http://www.joe.org/joe/2001august/a3.html

3. Wenger, E.: Communities of practice social learning systems. Organization 7, 225-256 (2000)

4. Fahy, P.J.: Indicators of support in online interaction. International Review of Research in Open and Distance Learning, 4 (2003),

http: //www.irrodl.org/index.php/irrodl/article/view/129/600 (accessed December 29, 2006)

5. Shea, P.J., Pickett, A.M., Peltz, W.E.: A follow-up investigation of teaching presence in the SUNY learning network. Journal of Asynchronous Networks 7, 61-80 (2003)

6. Levy, Y.: Comparing dropout and persistence in e-learning courses. Computers and Learning 48, 185-204 (2007)

7. Barsky, E.: Introducing Web 2.0: weblogs and podcasting for health librarians. Journal of Canadian Health Library Association 27, 33-34 (2006)

8. Conrad, R.M., Donaldson, J.A.: Engaging the Online Learner Activities and Resources for Creative Instruction. John Wiley and Sons, Jossey-Bass, San Francisco (2004)

9. Ley, T., Kump, B., Lindstaedt, S.N., Albert, D., Maiden, N.A.M., Jones, S.V.: Competence and Performance in Requirements Engineering: Bringing Learning to the Workplace. In: Proceedings of the Joint International Workshop on Professional Learning, Competence Development and Knowledge Management -LOKMOL and L3NCD Crete, Greece, October 2 (2006) 